http://jmscr.igmpublication.org/home/ ISSN (e)-2347-176x ISSN (p) 2455-0450 crossref DOI: https://dx.doi.org/10.18535/jmscr/v8i8.11

\title{
A Comparative Study on the Effectiveness of Topical Phenytoin Dressing with Conventional Vaseline gauze/Chlorhexidine Tulle Grasse Dressing in Donor area of Split Skin Graft patients in a tertiary care teaching hospital
}

\author{
Authors \\ Dr Sunil Kumar Mallanaik, Dr Siddharth Nayak K \\ Mysore MMCRI \\ Corresponding Author \\ Dr Sunil Kumar Mallanaik
}

\begin{abstract}
Introduction: Phenytoin is an antiepileptic drug used in the treatment of generalized tonic clonic seizures and complex partial seizures The stimulatory effect of phenytoin on connective tissue suggested an exciting possibility for its use in wound healing. This study aims to compare the effectiveness of topical phenytoin powder with Vaseline/Chlorhexidine tullegrasse dressing in hastening healing of donor area in post SSG patients.
\end{abstract}

Materials and Methods: A prospective case control study involving patients fulfilling inclusion criteria for a period of one year was done. Medical case file information was collected and used for comparision between two groups of patients, one group whose donor area of graft was dressed with Vaselinel Chlorhexidine Tulle grasse dressing and other phenytoin soaked gauze. Sample size was of 20 cases and controls each. They were reviewed serially at Days 5,10, 3weeks and 3months following surgery for graft uptake inspection and also daily for a week following surgery for their pain scale.

Results: Majority (70\%) of the patients in both groups were found to be in the age of 30-60 years. Almost half of the cases and controls had PIRA as indication 45\% of cases were hypoalbuminic and 35\% were anemic,35\% of controls were diabetic and 30\% were obese. Addictions such as smoking and alcoholism were similar in both groups. Most cases (75\%) and controls (95\%) showed complete healing and had completed follow up. All cases showed improved pain control and post operative comfort compared to controls.

Conclusion: We found that phenytoin dressing was a cheaper and easily available method when compared to other modalities. Though phenytoin dressing is inferior compared to newer modalities, it was superior in comparision to Vaseline/Chlorhexidine dressing with higher patient compliance greater pain relief faster healing rates and cost effectiveness. Further comparative studies with a wider study group with more coexistent comorbid conditions are required to further merit.

Keywords: Phenytoin, Seizures, Wound Healing, Chlorhexidine.

\section{Introduction}

Phenytoin is an antiepileptic drug used in the treatment of generalized tonic clonic seizures and complex partial seizures ${ }^{1}$. It is also recommended for the treatment and prevention of convulsions which occur during or after neurosurgery ${ }^{2}$. 
Phenytoin was introduced into therapy in 1937 for the appropriate control of convulsive disorders ${ }^{3}$. A very common side effect of phenytoin is development of fibrous overgrowth of gingiva called gingival hyperplasia ${ }^{4}$.This stimulatory effect of phenytoin on connective tissue has opened a new dimension for its use in wound healing 5 .

Wound healing is a complex process by which the physical integrity of internal or external body structures is restored and involves many complex interactions between the cells including various other factors ${ }^{6}$.The healing process consists of a sequence of overlapping events including complex inflammatory responses, epidermal regeneration, wound shrinkage and formation of connective tissue and remodeling ${ }^{6}$. In 1958, the beneficial effects of phenytoin in wound healing of epileptic patients with gingival hyperplasia was first observed by Shapiro. His conclusion was that collagen deposition required for wound healing was increased by phenytoin ${ }^{13}$.

In the stage of neovascularization phenytoin stimulates fibroblastic activities and other connective tissue components, as described by some investigators ${ }^{14,15,16}$. Furthermore, some investigators have suggested that phenytoin also hastens the wound healing process by inhibiting glucocorticoid activity, increasing alkaline phosphatase secretion and shortening the latent phase before maturation in wound healing ${ }^{17}$.In addition, Rovio ${ }^{19}$ and Shafer et al. ${ }^{18}$ have also reported the promoting effects of localized phenytoin administration, such as a significant increase in the wound tensile strength and an accelerated granulation formatting.

Some clinical studies suggest that the fibroblastic proliferation stimulation, increasing the formation of granulation tissue, promoting the deposition of collagen decreasing collagenase activity (by reducing its production or secretion or both) and other connective tissue components, decreasing the formation of wound exudate, and by decreasing the bacterial contamination are some of the ways by which topical phenytoin hastens the healing process ${ }^{7,8}$.Biopsies of open wounds treated by phenytoin also show neovascularization and collagenization ${ }^{7}$. Membrane stabilizing action of topical phenytoin therapy also provides local pain relief which has been observed in several studies 8,9 .

Topical application of phenytoin resulted in the direct access of the drug to the target site and it also avoided the risk of getting systemic side effects. The antibacterial activity of phenytoin also leads to the removal of Staphylococcus aureus, Klebsiella species, Escherichia coli, Pseudomonas ${ }^{10,11,12}$ which gives better graft uptake by improving graft bed quality.

This Study aims to exploit the above mechanisms of phenytoin to achieve a faster and pain free adequate wound healing when compared to conventional Vaseline gauze dressing to SSG donor site area.

\section{Materials and Methods}

The present study was conducted to study the effectiveness of topical phenytoin powder in fastening healing of donor area in post SSG patients and to compare the effectiveness of topical phenytoin powder with Vaseline/ Chlorhexidine tulle grasse dressing in healing donor area in SSG patients. A prospective case control study involving all patients with Post inflammatory raw wound following trauma, flap cover, burns, keloid excision fulfilling inclusion criteria admitted in tertiary care hospital during the time period from October, 2018 to June 2019 for a period of one year will be included for the study. A list of patients with their hospital numbers will be obtained from the admission and OPD registers and original medical case files traced from medical records department. Medical case files, reports of chest radiographs and laboratory investigations will be reviewed to obtain the necessary information about the presence of comorbidities, malnutrition and the inciting factors for wound formation. The information will be collected and used for comparision between two groups of patients, one 
group of patients whose donor area of graft will be dressed with conventional Vaseline soaked gauze/Chlorhexidine Tulle grasse dressing and other with gauze soaked with topical phenytoin. Sample size is of 20 cases and 20 controls. These patients will be reviewed serially at Days 5,10, 3 weeks and 3 months following surgery for graft uptake inspection and also daily after 1 week following surgery for their pain scale. Data obtained will be tabulated comparatively based on the days and the Data will be entered into SPPS version 21. Data will be presented as rates and proportions. Statistical significance of difference in proportions will be tested using chi square test, Cramer's V value and a p-value less than 0.05 will be considered as significant. Those patients whose age are $<18$ years and $>80$ years and who refuse the treatment are the exclusion criteria.

\section{Results}

1. Age distribution of cases and controls

We observed that majority of the study patients belonged to the 30-60 years age group (67.5\%) Among the patients in the 30-60 years age group, 13 were cases and 14 were controls.

Table 1: Age distribution of patients

\begin{tabular}{|l|c|c|}
\hline Age & Number of patients & Percentage \\
\hline$<30$ years & 7 & $17.5 \%$ \\
\hline $30-60$ years & 27 & $67.5 \%$ \\
\hline$>60$ years & 6 & $15 \%$ \\
\hline Total & 40 & $100 \%$ \\
\hline
\end{tabular}

Chi square value $=165.78 \mathrm{p}$ value $=0.003$ statistically significant $(\mathrm{p}<0.05)$

\section{2. a) Sex Distribution of Cases}

In our study we found that the number of males was more than the number of females in both the cases group and control group i.e 11 (55\%) to 9 $(45 \%)$

Table 2a: Sex Distribution of cases

\begin{tabular}{|l|c|c|}
\hline Sex & Number of cases & Percentage \\
\hline MALE & 11 & $55 \%$ \\
\hline FEMALE & 9 & $45 \%$ \\
\hline TOTAL & 20 & $100 \%$ \\
\hline
\end{tabular}

Chi square value $=123.64 \mathrm{p}$ value $=0.657$ not statistically significant $(\mathrm{p}<0.05)$ b) Sex distribution of controls

Table 2b: Sex Distribution of controls

\begin{tabular}{|l|c|c|}
\hline Sex & Number of controls & Percentage \\
\hline MALE & 11 & $55 \%$ \\
\hline FEMALE & 9 & $45 \%$ \\
\hline TOTAL & 20 & $100 \%$ \\
\hline
\end{tabular}

Chi square value $=123.64 \mathrm{p}$ value $=0.657$ not statistically significant $(\mathrm{p}<0.05)$

3. Serology of the patients-None of the patients were found to be HIV or HBsAg positive in our study.

4. Anemia in patients

In our study we found that 7 patients in the cases group (35\%) were anemic with $\mathrm{Hb}<10 \mathrm{gm} / \mathrm{dl}$ and 2 patients in the control group were also anemic $(10 \%)$

Table 3: Anemia in patients

\begin{tabular}{|l|c|c|c|}
\hline Patients & Anemic & Non Anemic & Percentage \\
\hline Cases & 7 & 13 & $35 \%$ \\
\hline Controls & 2 & 18 & $10 \%$ \\
\hline Total & 9 & 31 & 100 \\
\hline
\end{tabular}
ramer's V value =3.435 p value $=0.045$ statistically
ignificant $(\mathrm{p}<0.05)$

\section{Obesity in Patients}

We also found that in the cases group 3 patients $(15 \%)$ were obese with a BMI >25 and in the control group 6 patients were obese (30\%).

Table 4: Obesity in patients

\begin{tabular}{|c|c|c|c|}
\hline Patients & Obese & Non Obese & Percentage \\
\hline Cases & 3 & 17 & $15 \%$ \\
\hline Controls & 6 & 14 & $30 \%$ \\
\hline Total & 9 & 31 & 100 \\
\hline
\end{tabular}

\section{Diabetes in Patients}

In our study we found that 5 patients in the cases group were diabetic $(25 \%)$ and 6 cases in the control group were diabetic (30\%)

Table 5: Diabetes in patients

\begin{tabular}{|l|c|c|c|}
\hline Patients & Diabetic & Non Diabetic & Percentage \\
\hline Cases & 5 & 15 & $25 \%$ \\
\hline Controls & 6 & 14 & $30 \%$ \\
\hline Total & 11 & 29 & 100 \\
\hline
\end{tabular}

Cramer's V value $=5.68 \mathrm{p}$ value $=0.27$ not statistically significant $(\mathrm{p}<0.05)$ 


\section{Drug history in patients}

We also noticed that $60 \%$ of patients in the cases group and $40 \%$ of patients from control group took some form medication commonly being OHA's, Insulin, Antihypertensives and Iron supplements.

Table 6: Drug history in patients

\begin{tabular}{|l|c|c|c|c|c|c|c|}
\hline Patients & OHA & $\begin{array}{c}\text { Insu } \\
\text { lin }\end{array}$ & $\begin{array}{c}\text { Iron } \\
\text { meds }\end{array}$ & $\begin{array}{c}\text { Antihype } \\
\text { rtensives }\end{array}$ & $\begin{array}{c}\text { Asth } \\
\text { ma }\end{array}$ & $\begin{array}{c}\text { Epil } \\
\text { epsy }\end{array}$ & $\begin{array}{c}\text { Perce } \\
\text { ntage }\end{array}$ \\
\hline Cases & 3 & 1 & 3 & 2 & 2 & 1 & $60 \%$ \\
\hline Controls & 4 & 2 & 1 & 1 & 0 & 0 & $40 \%$ \\
\hline Total & 7 & 3 & 4 & 3 & 2 & 1 & $100 \%$ \\
\hline
\end{tabular}

Cramer's V value $=4.53 \mathrm{p}$ value $=0.13$ not statistically significant $(\mathrm{p}<0.05)$

8 . Addictions in patients

In our study we also noticed that $70 \%$ of patients had some form addiction i.e smoking or alcohol intake in the cases group and $80 \%$ of patients in the control group

Table 7: Addictions in patients

\begin{tabular}{|l|c|c|c|}
\hline Patients & Smokers & Alcoholics & Percentage \\
\hline Cases & 8 & 6 & $70 \%$ \\
\hline Controls & 10 & 6 & $80 \%$ \\
\hline Total & 18 & 12 & 100 \\
\hline
\end{tabular}

Cramer's V value $=1.93 \mathrm{p}$ value $=0.102$ not statistically significant $(\mathrm{p}<0.05)$

\section{Albumin in patients}

We also found that 9 out of 20 patients in the cases group had low albumin levels (45\%) and 2 out of 20 patients in the control group had low albumin levels (10\%)

Table 8: Albumin in patients

\begin{tabular}{|l|c|c|c|}
\hline Patients & Cases & Controls & Percentage \\
\hline$<3 \mathrm{gm} / \mathrm{dl}$ & 9 & 2 & $45 \% / 10 \%$ \\
\hline$>3 \mathrm{gm} / \mathrm{dl}$ & 11 & 18 & $55 \% / 90 \%$ \\
\hline Total & 11 & 29 & 100 \\
\hline
\end{tabular}

Cramer's $\mathrm{V}$ value $=4.53 \mathrm{p}$ value $=0.013$ statistically significant $(\mathrm{p}<0.05)$

10. Indication for SSG in patients

In our study we found that among the patients in the cases and control group most common indication is PIRA (post inflammatory raw area) i.e $11(55 \%)$ and $10(50 \%)$.

Table 9: Indication for SSG in patients

\begin{tabular}{|l|l|l|l|}
\hline Indication & Cases & Controls & Total \\
\hline PIRA & 11 & 10 & 21 \\
\hline Keloid Excision & 1 & 3 & 4 \\
\hline Flap cover Raw Area & 3 & 4 & 7 \\
\hline Burns & 5 & 3 & 8 \\
\hline Total & 20 & 20 & 40 \\
\hline
\end{tabular}

Chi square value $=186.94 \mathrm{p}$ value $=0.677$ not statistically significant $(\mathrm{p}<0.05)$

\section{Size of the defect}

In our study we found that in both the cases and controls group, 4 patients had a more than or equal to $10 \mathrm{~cm}$ wound dimension atleast on one side $(20 \%)$.

Table 10: Size of the defect

\begin{tabular}{|c|c|c|c|}
\hline Patients & Cases & Controls & Percentage \\
\hline $\begin{array}{l}<10 \mathrm{~cm} \text { in all } \\
\text { dimensions }\end{array}$ & 16 & 16 & $20 \%$ \\
\hline $\begin{array}{l}>10 \mathrm{~cm} \text { in any } \\
\text { one of the } \\
\text { dimensions }\end{array}$ & 4 & 4 & $20 \%$ \\
\hline Total & 20 & 20 & 100 \\
\hline
\end{tabular}

12. Concentration of Phenytoin used in our study for all 20 cases we used phenytoin in a concentration of $100 \mathrm{mg} / 100 \mathrm{ml}$.

\section{Pain scoring}

In our study we found that all patients in the cases group had a pain scoring scale of less than atleast 2 from day 0 when followed upto day 6 and also all patients in the controls group had a pain scoring scale of more than 3 from day 0 when followed upto day 6

Table 11: Pain Scoring

\begin{tabular}{|l|c|c|c|}
\hline Pain scoring scale & Cases & Controls & Percentage \\
\hline$<2$ & 20 & 0 & $100 \%$ \\
\hline$>3$ & 0 & 20 & $100 \%$ \\
\hline Total & 20 & 20 & 40 \\
\hline
\end{tabular}

Chi square value $=194.64 \mathrm{p}$ value $=0.047$ statistically significant $(\mathrm{p}<0.05)$

14. Visualized findings on follow up

We found that majority of patients in both cases and control groups showed normal healing ie 15 in cases (75\%) and 19 in controls (95\%).

Table 12: Visualized findings on follow up

\begin{tabular}{|l|l|l|l|}
\hline Patients & Cases & Controls & Percentage \\
\hline Healed & 15 & 19 & $25 \%$ \\
\hline Delayed Healing & 5 & 1 & $30 \%$ \\
\hline No Change & 0 & 0 & 100 \\
\hline Total & 20 & 20 & 40 \\
\hline
\end{tabular}

Chi square value $=158.64 \mathrm{p}$ value $=0.357$ not statistically significant $(\mathrm{p}<0.05)$

\section{Outcomes in patients}

We found that majority of patients in both cases $15(75 \%)$ and control 18 (90\%) groups had completed the stipulated follow up regimen 
Table 13: Outcomes in patients

\begin{tabular}{|l|c|c|c|}
\hline Patients & Cases & Controls & Percentage \\
\hline Completed & 15 & 18 & $25 \%$ \\
\hline Defaulted & 5 & 2 & $30 \%$ \\
\hline Total & 20 & 20 & 100 \\
\hline
\end{tabular}

Chi square value $=144.13 \mathrm{p}$ value $=0.524$ not statistically significant $(\mathrm{p}<0.05)$

Topical Phenytoin on Donor Site of SSG

\section{PROFORMA}

1.Name :

Phone No:

2.Age :

3.Sex :

4.Address :

5.IP/OP : Number -

6.HBsAG status:- a) Positive b)Negative c)Not done

7.HIV status : a) Positive b)Negative c)Not done 8.Nutritional status: Anemia/Obese

9.Co- morbidities if any :Diabetes, Malignancy, Jaundice, Uremia, Clotting Disorders

11.Drug History:-

12.Addictions:-Smoking/Tobacco

Chewing/Alcohol

13.Investigations done and reports ;

a) $\mathrm{Hb}$

b)TLC

c)Albumin

d)Radiological finding

e)Culture and Sensitivity

14.Indication for SSG:-

15.Concentration of Topical Phenytoin used:-

16. Size of the defect in square(recipient area) cm2:-

17.Visualized findings on Serial examination of Donor Area

\begin{tabular}{|l|c|c|}
\hline Day of Surgery & $\begin{array}{c}\text { Vaseline Gauze/ } \\
\text { Chlorhexidine Sofra } \\
\text { Tulle Grasse Dressing }\end{array}$ & $\begin{array}{c}\text { Topical } \\
\text { Phenytoin } \\
\text { Dressing }\end{array}$ \\
\hline Day 5 & & \\
\hline Day 10 & & \\
\hline 3 weeks & & \\
\hline 3 months & & \\
\hline
\end{tabular}

Healed/Granulating wound/Infected/Necrosis/No Change
18. Pain scale

\begin{tabular}{|l|l|}
\hline DAY & FINDINGS \\
\hline 0 & \\
\hline 1 & \\
\hline 2 & \\
\hline 4 & \\
\hline 5 & \\
\hline 6 & \\
\hline 7 & \\
\hline
\end{tabular}

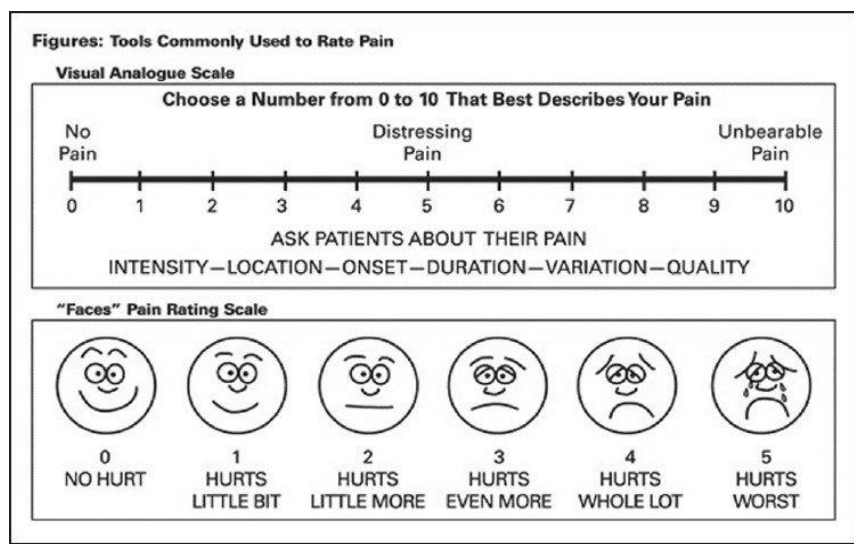

19. Outcome
A) Completed and Hastened
B) Completed and Failed
C) Completed and Equivocal
D) Default

20. If Default, at what stage of therapy did it take place-

\section{Discussion}

In our study we found that in the cases group majority of the patients were male $(55 \%)$ and belonged to the middle age group 30-60 years $(67.5 \%)$. About $35 \%$ were anemic, $25 \%$ were diabetic and $15 \%$ were obese. $60 \%$ of cases had co existent comorbidities and consumed medications. Also 45\% had a low albumin level. Majority of cases group patients had Post inflammatory raw area as the most common indication for grafting. All patients had been applied with phenytoin soaked gauze dressing of concentration $100 \mathrm{mg} / 100 \mathrm{ml}$.All the cases had pain scoring scale of 2 or less from day 0 to day 6 follow up. $75 \%$ of the cases had completed follow up to 3 months and were healed.

A review study comprising of 33 studies found that the transparent films were the best dressing 
material for the care of STSG donor site wounds. Transparent films were found to have a smooth epithelialized surface and to be associated with one of the fastest healing rates of (9.47 days), the least amount of pain (1.59 on 0 to 10 scale), minimal cost of ( $\$ .005$ per square inch) and a lower infection rate of (10 out of 394 patients or $3 \%)$ when compared with all the other dressings ${ }^{20}$. Another study concluded that Phenytoin plus Vaseline dressings were significantly more effective as compared to vaseline alone dressings in healing of diabetic foot ulcers. Phenytoin powder was found to be cheaper and easily available which can be applied topically on the ulcers and hence it can be used in resource-poor environments but further clinical use and evaluation is required $^{21}$.

A study concluded that adhesive retention dressings are less painful more comfortable, easier care can be given, requiring less nursing intervention and allow a greater range of activities and mobility than the current standard of calcium-alginate dressing for split-skin-graft donor sites, which does not compromise wound healing ${ }^{22}$.

They also concluded that the difference in pain scores was related to the bulk, mobility, and thickness of the dressings. In the alginate dressings, it was found that there blood seepage through the alginate and clots developed in the layers of supporting gauze. This resulted in the formation of a very stiff adherent thick immobile block of tissue which was attached to the donor site. This block of dressing caused irritation of the underlying donor site. By comparison, the retention dressing allowed blood seepage onto the gauze, but this clot was not adherent and which could be easily removed after 24-72 hours, leaving the attached dressing as a very thin mobile layer. The increased pliability reduced pain and lack of bulk of the retention dressing helped to increase the mobility of patients and greater ease of independent living. This could be seen in the reduced scores given by those patients with retention dressings when asked about hygiene and activities of daily living. Patients with these retention dressings are able to shower and bathe. The dressings can be left to air dry or dry patted. The gauze padding on the alginate dressing allows it to not get wet and avoids the risk of macerating the underlying skin. Alginate dressings require twice the nursing intervention when compared to retention dressings. Generally this was due to the persistence of the gauze, the pad bulk of the dressing and the difficulty of maintenance of nonadherent dressings on the tapering thigh. Slipped dressings repadding and rebandaging, interventions contribute to interference with activity and symptomatology 22 .

Yadav J.K et al concluded that OpSite and phenytoin were much superior when compared to the Soframycin dressing with respect to wound infection and bacterial contamination as measured by Gram stains of wound smears, aspirate and swab (OpSite) cultures, and clinical assessments were carried out on the fifth day of treatment. These three agents showed no local or systemic adverse effects when used. Phenytoin seems to be a low-cost effective, and safe method for the treatment of partial-thickness skin graft donor sites, having favourable results comparatively and also superior results to occlusive dressings. Further clinical use and evaluation of topical phenytoin were required ${ }^{23}$.

A study also found that patient compliance, granulation tissue formation rate and overall graft survival was better in topical phenytoin dressing group when compared to the conventional dressing group. It was also seen that the postoperative complications and overall hospital stay was less in the topical phenytoin dressing group. Thus, topical phenytoin moist wound dressing can be taken as a superior option in the diabetic ulcer management ${ }^{24}$.

\section{Conclusion}

In our setup we found that phenytoin soaked gauze dressing was a cheaper and easily available method for dressing of SSG donor site areas when compared to other modalities of dressing such as 
transparent film dressings, foam dressings, hydrogel and hydrocolloid dressings, oxidized cellulose, alginates, hydro conductive dressings and silicone dressings. Though phenytoin gauze dressing is inferior compared to newer modalities transparent film and hydro conductive dressings, our study showed that it was superior in comparision to Vaseline/ chlorhexidine impregnated gauze dressing showing a higher patient compliance, greater pain relief and faster healing rates and being cost effective .Though further comparative studies with a wider study group with more coexistent comorbid conditions are required to further merit.

\section{Conflict of Interest- None}

\section{References}

1. Dilantin. New York, New York: Pfizer Inc; Aug 2012. www.hsa.gov.sg. Accessed 3 June 2013.

2. Dilantin. New York, New York: ParkeDavis (Division of Pfizer Inc); Jan 2012. http://www.accessdata.

fda.gov/drugsatfda_docs/label/2012/08434 9s067lbl.pdf Accessed 3 June 2013

3. Bhatia A, Prakash S. Topical phenytoin for wound healing. Dermatol Online J 2004; 10:5.

4. Antiepileptic drugs. In: KD Tripathi (ed). Essentials of Medical Pharmacology, 6th edition. Jaypee Brothers; 2008. p. 382-5.

5. Thompson S, Mary N, Fredrick G. Topical Phenytoin ointment for surgical wounds. Ann Pharmacol 1994;24:552-4.

6. Alizadeh A, Mohagheghi M, Khaneki M, Saeed PK. A study of the effect of magnesium hydroxide on the wound healing process in rats. Med $\mathrm{J}$ Islamic World Acad Sci 2007;16:165-70.

7. McAnally LE, Thompson D. Use of phenytoin for wound healing. Hosp Pharm 1992;27:649-50.

8. Rhodes RS, Heyneman CA, Culbertson VL, Wilson SE, Phatak HM. Topical phenytoin treatment of stage II decubitus ulcers in the elderly. Ann Pharmacother 2001;35:675-81.

9. Talas G, Brown RA, McGrouther DA. Role of phenytoin in wound healing-a wound pharmacology perspective. Biochem Pharmacol 1999;57:1085-94.

10. Reiber GE, Vileikyte L, Boyko EJ, del Aguila M, Smith DG, Lavery LA et al. Causal pathways for incident lowerextremity ulcers in patients with diabetes from two settings. Diabetes Care 1999; 22:157-62.

11. Rituraj, Aggarwal S, Chatterjee S. Topical phenytoin: role in diabetic ulcer care. International Journal of Interdisciplinary and Multidisciplinary Studies. 2015; 2(6):93-7.

12. Jayalal JA, Kumar SJ, Dhinesh, Thambithurai D, Kader JMA. Efficiency of Topical Phenytoin on Healingin Diabetic Foot Ulcer: A Randomized Controlled Trial. Int J Sci Stud. 2015; 3(3):84-9.

13. Shapiro M. Acceleration of gingival wound healing in non-epileptic patients receiving diphenylhydantoin sodium (dilantin, epanutin).Exp Med Surg. 1958;16(1):41-53. [PubMed: 13537920].

14. Chikhani P. Use of sodium phenytoin in the treatment of periodontal diseases [ in French]. Actual Odontostomatol (Paris). 1972;26(98):265-74. [PubMed: 4539797].

15. Simpson GM, Kunz E, Slafta J. Use of Sodium Diphenylhydantoin in Treatment of Leg Ulcers. N Y State J Med. 1965;65:886-8.

16. Savini ECPR, Poitevin J. New treatment of periodontolysis. Rev France Odontostomatol. 1972;26(98):265-74.

17. Kelln E, Gorlin R.Healing qualities of an epilepsy drug.DentalProg.1961;1:126-9.

18. Shafer WG, Beatty RE, Davis WB. Effect of dilantin sodium on tensile strength of 
healing wounds. Proc Soc Exp Biol Med. 1958;98(2):348-50

19. Rabio J. Diphenyl hydantoin in leprosy. Oazaca, Mexico: 12 congress of dermatology; 1985.

20. Split-thickness skin graft donor site care: a quantitative synthesis of the research $\mathrm{RN}$ Barbara et al Applied Nursing Research Volume 11, Issue 4, November 1998, Pages 174-182

21. A comparison of efficacy of topical use of phenytoin and vaseline gauze dressing with vaseline gauze dressing alone in healing of diabetic foot ulcers Ahmed A, Ahmed M I Journal of Postgraduate Medical Institute (Peshawar - Pakistan) Vol 28 No 3 (2014) Original Article

22. Adhesive retention dressings are more comfortable than alginate dressings on split-skin-graft donor sites E Hormbrey, A Pandya, H Giele JPRAS July 2003 Volume 56, Issue 5, Pages 498-503

23. Topical phenytoin in the treatment of splitthickness skin autograft donor sites: a comparative study with polyurethane membrane drape and conventional dressing. K. Yadav A.M. Singhvi N. Kumar S. Garg Burns. 1993 Aug;19 (4):306-10.

24. Efficiency of topical phenytoin on healing in diabetic ulcer: a randomized control trial. Jayaraman Selvaraj, Solaiappan Jeevaraman Journal of Evolution of Medical and Dental Sciences(Vol. 5, Issue 23). 